\title{
The Current Status of the Consumer Electronics Repair Industry in the U.S.: A Survey-based Study
}

\author{
Mostafa Sabbaghi $^{\text {a }}$, Willie Cade ${ }^{c}$, Sara Behdad ${ }^{\text {a, b }}$ Ann Bisantz ${ }^{\text {a }}$ \\ ${ }^{a}$ Industrial and Systems Engineering Department, University at Buffalo, SUNY, Buffalo, New York, U.S.A. \\ ${ }^{\mathrm{b}}$ Mechanical and Aerospace Engineering Department, University at Buffalo, SUNY, Buffalo, New York, U.S.A. \\ ${ }^{\mathrm{c}}$ PC Rebuilders \& Recyclers Inc., Chicago, Illinois, U.S.A.
}

\begin{abstract}
Consumer electronics are turning into consumable devices nowadays, and consumers generally show little inclination to repair broken products due to the lack of repair infrastructures and relative high repair costs. On the other hand, technical, operational, and economic barriers impede the growth of repair businesses. In this paper, we provide a look into the repair industry through an analysis of a survey conducted by a third-party repair service provider. 2170 repair technicians have participated in a survey consisting of 23 questions about repair challenges in their profession. At first, we take a look at the economic barriers that dissuade consumers from repairing products. Next, a demand-based repair service pricing framework is introduced. The optimal pricing levels are found based on the consumers' repair demand. Finally, other aspects of repair businesses, e.g. repairability degree of consumer electronics and consumer expectations of repair services, are thoroughly investigated. As an example of findings, different types of consumer electronics are clustered based on the associated repair difficulties. Moreover, some insights are provided to promote the repair businesses.
\end{abstract}

Keywords: Consumer Electronics, Repair Business, Service Pricing, Design for Repair, K-means Clustering, Consumer Behavior

\section{Introduction}

In a "throw-away society" with short-lived products and consumers' over-consumption behavior [1], the repair activities may fall into decline gradually due to factors such as the high cost of labor and spare parts. The costly repair services dissuade consumers from repairing their obsolete products [2], even when the consumers may favor repair over disposal [3]. The repair workforce will shrink even faster in the developed regions since the labor cost is drastically higher than the cost in developing regions [4]. Reported by the U.S. Census Bureau, the number of annually-stablished firms in the consumer electronics repair and maintenance industry (NAICS code 811211 ${ }^{1}$ ) has decreased from 4623 in 1998 to 2072 in 2015. In a survey conducted by Wei et al. [5], 50\% of car remanufacturers pointed out that hey have problem with accessing the well-trained and skilled but cheap technicians in China that has been known for a long time as a place for low-cost labor.

There is a consensus among the electronic waste (e-waste) research community that a significant proportion of used equipment generated in developed countries is exported to developing countries for recycling activities [6], [7]. It is hard to track the way in which the exported equipment will be recovered in their destinations. However, for the case of unwiped disposed data storage devices, the data stealing that may result in cybercriminals shows that the devices were still functional and being reused somehow

\footnotetext{
${ }^{1}$ Source: The United States Census Bureau, The North American Industry Classification System, http://www.census.gov/eos/www/naics/
} 
[8]. Although a significant number of discarded products seem to be reusable, it has been observed that $75 \%$ of PCs exported from the U.S. to Nigeria are not reusable and just being recycled [9] due to a long delay in issuing the export-import license which results into the technological obsolescence and the unavailability of spare parts [10].

In a typical repair process, the nonfunctional products are brought into repair shops, when often the level of needed repair is not clear before a laborious troubleshooting is performed. The repair businesses, furthermore, suffer from the barriers of technical, operational and logistical limitations, e.g. lack of repair manuals, inappropriate repair tools, and unavailability of spare parts. Whatever the repair issues are, consumers expect that their broken products will be repaired fairly quickly and accurately for a reasonable cost [11]. However, there might be a risk that the repair shops come into conflict with the clients since they sometimes do not elucidate what outcomes may possibly be associated with the repair process. When consumers' expectations of repair outcome are not met, an aversion to repair products may develop [12]. For example, consumers would rather replace an obsolete product with a new one, which leads to more generation of End-of-Use /Life (EoU/L) items [13].

As a certain right, consumers and independent repair businesses should be aware of the products' repairability at the time of purchase. The independent repair businesses and initiatives, e.g. the Digital Right to Repair Coalition, have formed worldwide campaigns against the profit-driven policies of manufacturers and urge them to produce more repairable electronics, share the repair guides, and supply the spare parts in the market. The contemporary repair groups, e.g. Repair Café, motivate consumers toward products' repair as an advance sustainable practice [14]. Furthermore, the waste reduction strategies, such as the Circular Economy, are motivated by many governments, which promotes repair and reuse as the first lines of defense against waste [15].

Using a survey-based approach, we aim to explore the obstacles that the consumer electronics repair businesses encounter and quantify their impacts on the performance of the repair industry. The findings of this study together with the addressed issues have potential implications for future research in repair businesses, green product design and manufacturing, and consumer purchase and post-purchase behavior.

The rest of this paper is organized as follows. The prior literature is reviewed and the research gaps are discussed in Section 2. Next, the methodology of the research study is explained. A brief overview of the conducted survey is provided in Section 4. After quantifying the uncertainty of the repair labor cost, a demand-based repair services pricing model is presented to determine the optimal per-time-unit labor cost based on the repair demand in Section 5. In this section, a sensitivity analysis on the spare parts supply is provided for further insights. In the subsequent sections, the repairability of the current consumer electronics, the design of repair tools, enhancing the skills of repair workforce, the clients' expectations of repair services, and the potential role of repair businesses in raising the public awareness about repair are comprehensively discussed, respectively. In Section 9, the lessons learned from the repair businesses are summarized. Finally, we conclude the paper by outlining some possible steps for the future research.

\section{Literature Review}

Research on making policies to promote efficient consumption of resources is going beyond the traditional techno-economic business modelling approaches. Now, it is also studied from a wide spectrum of aspects - including the cultural phenomena of sustainable practices like local repair comunities [16] and behavioral decision-making process (e.g., capturing consumers' repair behaviors [17]). In fact, social impacts and attitudes towards such green policies are also of great importance to develop a successful sustainable business model [18]. Hence, it is essential to identify what matters most to consumers' 
willingness to receive green services, as well as the main operational and technical-driven challenges and barriers that the businesses may encounter in interacting with other stakeholders. In this section, we first review the literature relevant to the repair businesses from social, technical, and economic research perspectives. Next, it is described how this paper will contribute to the growing attention towards repair of products as promising solutions to use resources more efficiently.

As mentioned in the Introduction, the relatively high cost of repair and falling cost of product replacement [19] are the main deterrent to repair broken products. Hence, the repair businesses need to efficiently set a demand-based repair service pricing strategy. Although consumers often care about the costs of their repair decisions, other contributory factors such as consumers' perception of the product' technological and functional obsolescence [20], and psychological factors [21] are important in the decision-making process. Consumers may even throw a nonfunctional device away since it does not seem repairable.

McCollough [22] proposed an analytical model, where the individual repair/replacement decision is made based on the discounted net benefits of repair and replacement over the use cycle of a product. Hence, the repair businesses must keep track of changes in prices of products together with consumers' preferences, perspectives, and their attitudes toward repair and replacement to carry out a fair value appraisal of repair services. To address this point, Calabrese and De Francesco [23] explained how the service firms would benefit more from implementing a demand-based service pricing approach rather than just adopting a cost-based pricing policies. In another study, the consumers' loss aversion toward price and delay in receiving services is considered in price modeling [24]. The delay is more important when the full-service contracts, in which the consumers pay a fixed fee for the periods of time (compared with the on-call services that consumers are charged based on the time and materials used for the repair). Huber and Spinler [25] proposed a model to determine the optimal pricing of the full-service contracts. The optimal pricing strategy is very sensitive to the volatility of failure events, repair time and cost.

The way that the repair services are provided influences the consumers' referral behavior, in which consumers' dissatisfaction with the repair services equates to reduced repair demand [9], [26]. Consumers usually express dissatisfaction through direct complaints, but it is not always the case. Ro [27] reported that factors such as attitude toward complaining, affectional bond, and failures criticalness distinguish non-complainer, patience, and neglect consumers from the complainers. She also compared the return intentions of consumers based on their reactions to receiving imperfect services.

The amount of time that a technician spends on repairing a device determines the associated labor cost. Among all factors that prolong the repair time, e.g. repair skills, the product repairability is a critical factor [28] that should be considered in the early phase of product design. To give an example, Coulibaly et al. [29] developed an approach to evaluate the maintainability and safety of a product using the information of components' reliability and disassembly-repair-assembly process decomposition. Recently, the estimation of the mean time to manually dismantle [30] and the mean time to generally repair the products [31], disassembly path planning [32], ergonomic repair process design [33], and experience-based monitoring of product repairability [34] have been getting attention in the sustainable design literature.

The unavailability of spare parts (or limited access to them) is another obstacle in the repair industry. The spare parts may be available over the large-scale manufacturing life cycle of the products. Once the manufacturers put an end to the production, the products are no longer available in the market. However, 3D printing is going to be a suitable solution to produce the spare parts in order to reduce the supply cost [35]. To overcome this adversity, repair businesses should find a way to manage their stock inventory. To 
try to deal with this issue, Käki [36] presented a procurement strategy to help repair firms determine the quantity of final order to make sure of the spare parts' availability for the repair services' operations. The spare parts are sometimes not available at all or made available to authorized repair centers. Therefore, the repair shops have to rely on aftermarket parts or harvest working components from broken devices, which are unreliable or hard at scale. The manufacturers refuse to make the repair information public, preferring instead to hold formal training courses for repair businesses. As a consequence of limited information, the independent repair shops basically grow their repair skills through the informal training systems, practical learning, and social network of repair community, specifically in developing countries [37].

To conclude, the literature so far addresses different topics about the repair industries (e.g. capturing the consumers' propensity for repair, quantifying the products' repairability, and improving the repair process itself), however, to the best of our knowledge, this is the first empirical study that takes a look at the current consumer electronics repair and maintenance business in the U.S. that faces with a fastgrowing electronic waste stream. In this paper, we not only provide fresh insights into the current status of consumer electronics repair industry, we also propose a demand-based repair service pricing model and a clustering analysis on repairability levels of different consumer electronics. The results of this study can be useful to bolster the repair businesses and promote the sustainable behavior among society through facilitation of repair operations and services.

\section{Methodology}

Given the fact that the survey data were already collected by a third party service provider not by the authors, the research methodology of this study is designed in a way to extract the most out of the experience-based view of professional repair technicians reported in the survey. First, a list of research gaps and research questions were identified by the authors. Then, the survey questions were reviewed carefully and mapped to the research questions and research gaps. The scheme, therefore, was to identify the research gaps and see which question(s) in the survey may lead to informative data for use in filling those gaps. The research questions are identified to mainly evaluate the economic, technical, and social

aspects of the consumer electronics repair practices. The main research questions that could potentially be answered using the survey data are as follows:

- What is the likelihood that the repair labor cost would exceed an upper bound that dissuades a consumer from repairing a broken device?

- How to set the repair services pricing strategy such that it creates more demand considering the consumers' willingness to repair and the cost of spare parts?

- What are common repair difficulties?

- Are the repair instruments designed effectively? What are the potentials to improve repair tools and instruments?

- How useful is the formal training of repair workforce from the repair technicians view point?

- How can the independent repair businesses raise the public awareness about the repair?

The further details on these questions are discussed in the following sections. The statistical and data mining techniques have been used to answer the questions using survey data. The input data for each model has been extracted and prepared from a set of questions in the survey. The findings are then interpreted to provide helpful insights. The interpretation of the findings is done based on the opinions of the experts in the fields of consumer electronics repair industry and e-waste recovery systems, in addition to the available literature. 


\section{Survey Overview}

This study is based on a survey conducted by iFixit.com. This survey contains data collected from 2170 repair technicians who visited iFixit website and provided their viewpoints on the consumer electronics repair activities. The geographical distribution of the respondents from the US was as follow: 15\% from California, 8\%, 7\%, 5\%, 4\%, and 3\% from New York, Texas, Florida, Pennsylvania, and Illinois respectively. The rest of respondents are spread across the other states. It should be noted that we have a few respondents from other countries; however, they were not included in the analyses to decrease the heterogeneity within the group under study. The SurveyMonkey platform was used to create the survey. The respondents introduced themselves as an employee working in the IT departments (52\%), or independent repair businesses (48\%). In 2015, the total employees in electronic and precision equipment repair and maintenance (NAICS code 8112) that has four sub-categories-including consumer electronics repair and maintenance were 141,000. Let's assume that one-fourth of them are consumer electronics repair technicians. Then, for a confidence level of $95 \%$ and a margin error of $1 \%$, a representative sample size of repair technicians should be 7548. If we accept that the deviation of population's responses from our sample's be higher (margin of error is $2 \%$ ), a representative sample size is 2248 that is very close to our sample size. Thus, although the sample size of the current paper may not be the representative for all repair technicians, is fairly large and enough.

The questionnaire contains numerous questions about the common issues that the repair businesses encounter. Table 1 summarizes the questions together with the initial number of responses on each question. It should be noted that not all participants have answered all the questions. In addition, we remove the incomplete, ambiguous, incorrect, or improperly formatted responses from the database. The remaining data is then used for research purposes.

People deem the repair services are exclusively offered by the common repair shops. It is surprising that nowadays the number of at-home workshops is growing fast. They fix the products inside their home with occasional client house call or trade-in on e-commerce or classified websites, and the products mainly belong to clients who trust at-home workshops. In some cases, they acquire the used products from the second-hand market, and then repair it for resale, e.g. collecting empty cartridges for currently owned printers. A few respondents count repairing as a hobby in their leisure time. Mobile repair service

is another mode of repair services offered to clients. At-home repair businesses together with the mobile repair ones are categorized as the informal repair businesses. However, the formal repair shops and service depots are still the most recognized groups in comparison with the other repair businesses. Fig.1 shows the revealed diversity in the repair businesses according to the sample data that we have (1045 respondents). The average number of employees of the at-home workshops, mobile repair services, retail repair shops, and service depots are $1.3,1.8,3.7$, and 4 , respectively. 
Table 1 Summary of the survey questions.

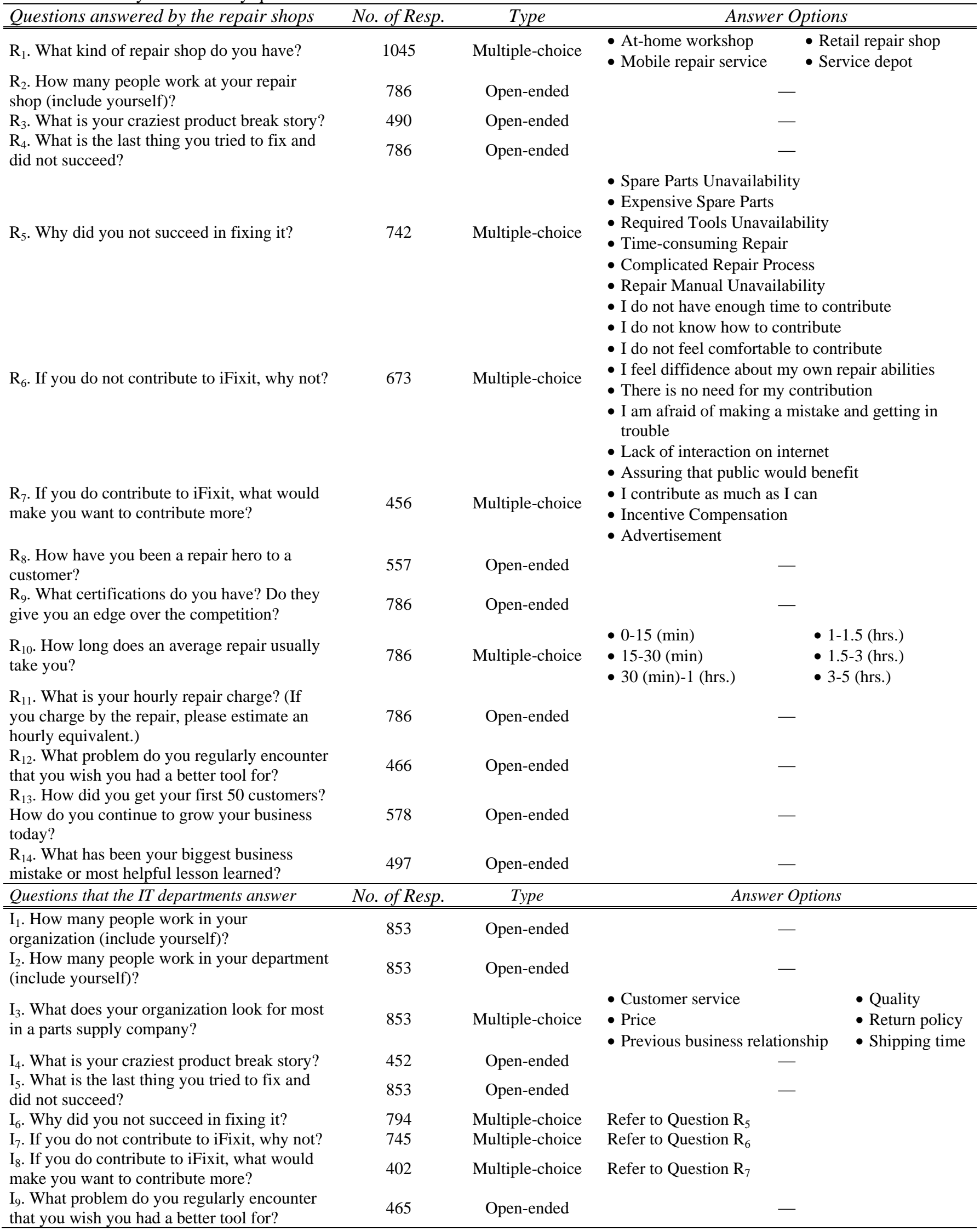




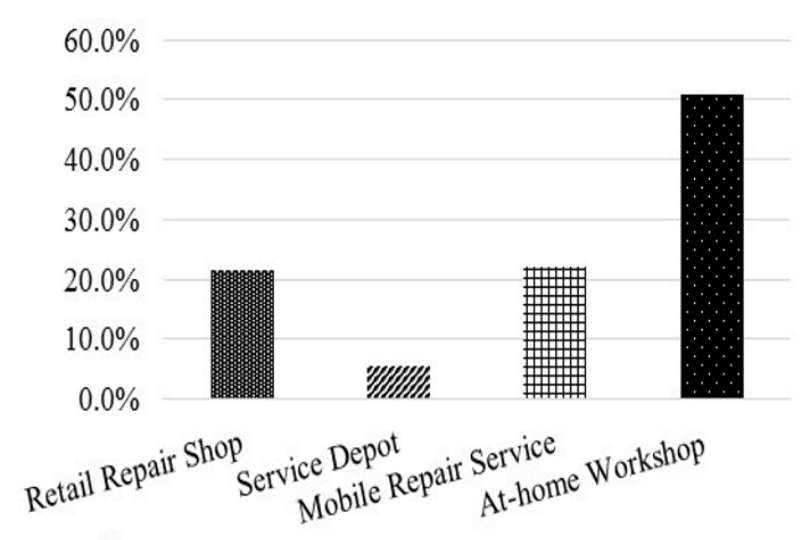

(a)

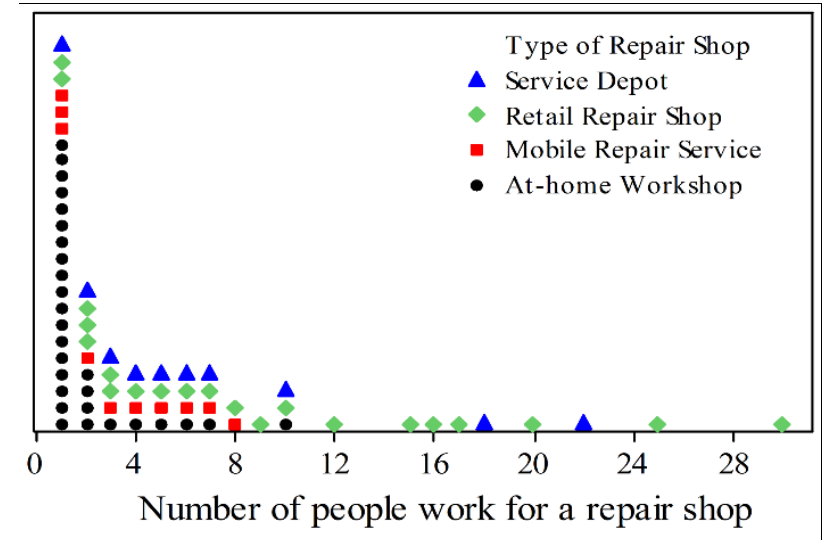

(b) Each symbol represents up to 19 observations.

Fig. 1 (a) Different types of independent repair businesses and their percentages among the respondents. (b) The distribution for the number of employees hired by independent repair businesses.

The service or repair department is often a support unit within the organizations, e.g. IT departments. The 1125 respondents who are employed as repair technicians were asked about the number of employees worked in their repair departments and also the total number of employees inside their firms. In our dataset, $4.6 \%$ of the total firms' employees are working for the IT departments on average. The box plot in Fig. 2 represents the distribution for the ratio of the number of repair staffs to the total number of employees in the firms. The scatter plot in Fig. 2 shows this percentage based on the number of total employees.

This information simply reflects the current status of the repair business, although it does not mean that we can easily generalize it to the whole repair community. For example, some repair technicians in less developed regions might not see the survey because of the limited access to internet. It would not be a valid assumption that all repair technicians have the same level of skills. As another limitation, therefore, the responses might be biased by the repair technician's skill level. The technicians who work for IT departments and educational setting might have answered the questions conservatively due to their commitment to their organizations. In some particular questions, for example the question that the repair technicians commented about the consumer's satisfaction of their repair services, the answers might be biased by the technicians' opinions, although we assume that the respondents answered the question based on the receiving feedback from the consumers. The above-mentioned points are some limitations of this survey that would affect the interpretation of the findings.

In the following sections, we evaluate the consumer electronics repair industry from different aspects, e.g. economic, technical, operational, and social points of view. In each section, the related questions are presented together with the analyses. The first part of the analyses is dedicated to the economic aspect of repair practices. 


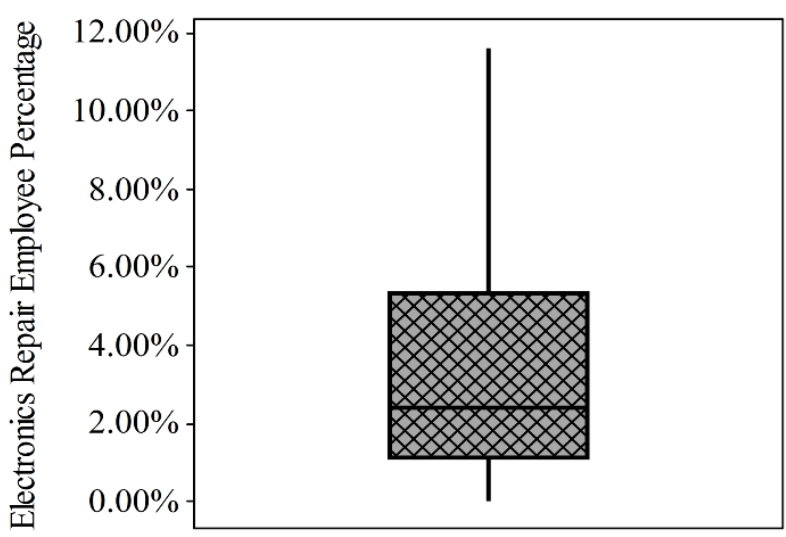

(a)

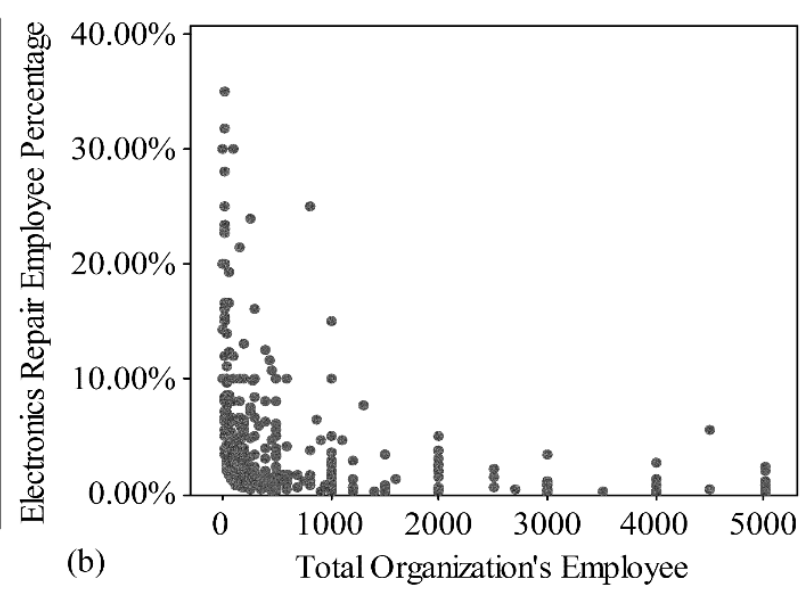

(b)

Fig. 2 (a) the box plot for the ratio of the number of repair staffs to the total number of employees in the firms. (b) The ratio of the number of repair staffs to the total number of employees and its relationship with the size of firms.

\section{Economic Aspects of Repair}

In this section, an overview of the economic aspect of repair is provided. Besides the quality of repair services, the cost and time of repair are among the factors that influence the consumers' attitude toward repairing products. In this section, we aim to capture the uncertainty in repair labor cost of consumer electronics and combine it with the repair demand function to optimize the pricing strategy of the repair services. First, the labor cost is estimated by querying the labor cost per unit of time and repair time and finding the distributions that represent the variation. Next, the product distribution of the independent marginal distributions is obtained to calculate the probability that the total repair labor cost would not exceed a specific amount. In the second part, a demand-based repair service pricing model is developed to determine the optimal value for the labor cost per unit of time and total repair profit considering the cost of spare parts. Finally, the impact of spare parts' cost on the optimal pricing policy is assessed to see how the spare parts' supply strategy may support or weaken the independent repair businesses.

\subsection{Estimation of the Repair Labor Cost}

To estimate the repair labor cost, the survey respondents have been asked two questions:

- 'What is your hourly repair charge? (If you charge by the repair, please estimate an hourly equivalent.)'

- 'How long does an average repair usually take you?'

These questions are open-ended and multiple-choice, respectively. Obviously, the repair time varies among the different electronic devices. Therefore, regardless of the type of broken device, the survey respondents were asked to estimate the average repair time (Fig. 3). The repair time consists of the time taken to identify the faults, disassemble the device, remove the broken parts and replace them with new ones, test the functionality, and finally reassemble the product. The time intervals are unequal, ranging from 15 minutes to 2 hours. These intervals are selected intentionally in such a way that makes sense in practice. For example, correction of minor software errors in a smartphone may possibly take a very short time, while repairing a water-damaged smartphone is likely to be much more time-consuming process.

The labor cost per unit of time varies across the repair businesses (Fig. 4). This hourly repair charge is estimated by the repair shops. The total labor cost is defined as the product of the repair time and the pertime-unit labor cost. However, it is not that much easy to find the probability density function (PDF) of 
the total repair cost, even if we know the PDF of each variables. Assume that $f(t)$ and $g(c)$ have been used to show the distribution of repair time $t$, and the per-time-unit labor cost $c$. Therefore, the distribution of the total labor cost $h(v)$ is the product of $f(t)$ and $g(c)$ and is obtained as follow:

$$
h_{V}(v)=\int_{0}^{\infty} h_{T, C}\left(t, \frac{v}{t}\right) \frac{1}{t} d t
$$

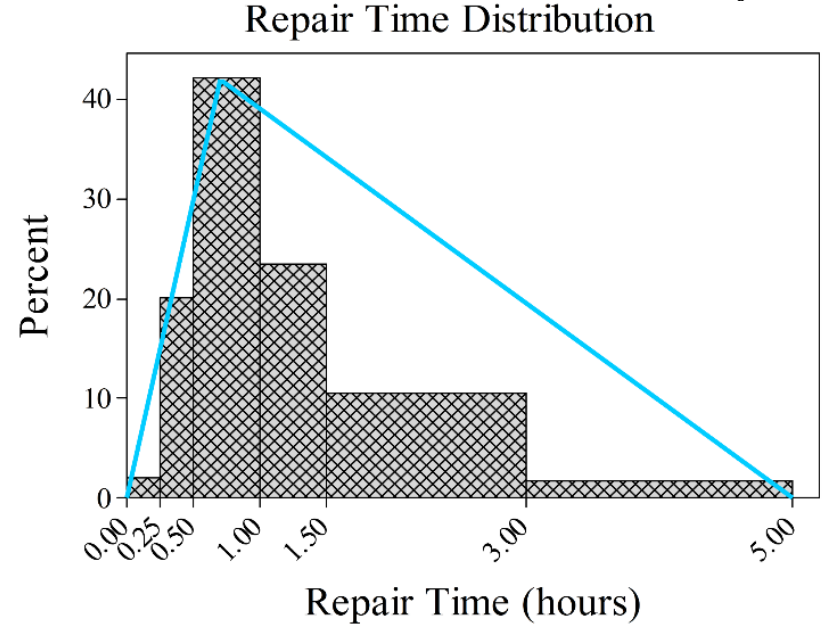

Fig. 3 The distribution of the consumer electronics' repair time based on the technicians' expertise.

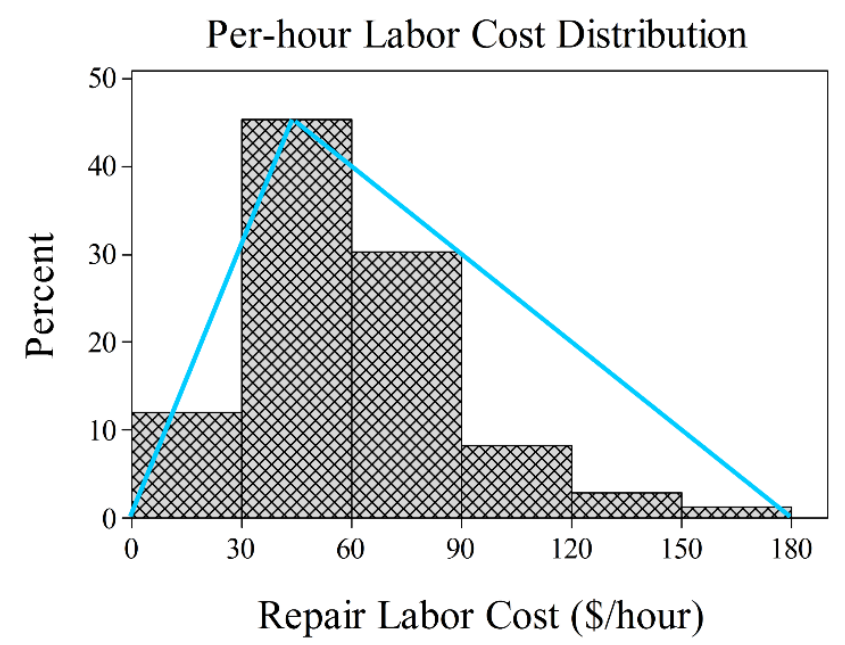

Fig. 4 The distribution of the labor cost per unit of time.

According to Figures 3 and 4, two triangular PDFs are used to represent the distributions of the labor cost per unit of time $c$ and the repair time $t$. The results of one-way ANOVA test ( $p$-value $=0.333$ ) shows that the two variables $c$ and $t$ are independent. The two triangular distributions have been fitted to the data as listed in Eq. 2. The variable $t$ ranges between 0 and 5 (hrs.) and the variable $c$ ranges between 0 and 180 (\$/hour).

$$
f(t)=\left\{\begin{array}{ll}
\frac{2 t}{5 \times 0.75} & 0 \text { (hrs.) } \leq t \leq 0.75 \text { (hrs.) } \\
\frac{2(5-t)}{2 \times 4.25} & 0.75 \text { (hrs. }) \leq t \leq 5 \text { (hrs.) }
\end{array}, g(c)=\left\{\begin{array}{cc}
\frac{2 c}{180 \times 45} & 0(\$ / \text { hour }) \leq c \leq 45(\$ / \text { hour }) \\
\frac{2(180-c)}{180 \times 135} & 45(\$ / \text { hour }) \leq c \leq 180(\$ / \text { hour })
\end{array}\right.\right.
$$

The distribution of the total labor cost $h(v)$ that is defined as the product of variables $c$ and $t$ (Eq. 3) can be obtained as suggested in Glickman and $\mathrm{Xu}$ [38]:

$$
h(v)=h(t, c)=f(t) \cdot f(c)
$$

According to their results, the sub-functions $h_{i}(v), i=1, \ldots, 4$ are defined based on the different combination of repair time and per-time-unit labor cost values as follows:

Where 0.01 (hrs.) $\leq t \leq 0.75$ (hrs.) and 1 (\$/hour) $\leq c \leq 45$ (\$/hour), we have:

$$
h_{1}(v)=\left\{\begin{array}{cc}
1.38 \times 10^{-4}\left[2(0.01-v)+(0.01+v) \ln \left(\frac{v}{0.01}\right)\right] & \$ 0.01 \leq v \leq \$ 0.45 \\
1.38 \times 10^{-4}[-0.44-0.98 v+3.81(0.01+v)] & \$ 0.45 \leq v \leq \$ 0.75 \\
1.38 \times 10^{-4}\left[0.036 v-1.2+(0.01+v) \ln \left(\frac{33.75}{v}\right)\right] & \$ 0.75 \leq v \leq \$ 33.75
\end{array}\right.
$$

Where 0.01 (hrs.) $\leq t \leq 0.75$ (hrs.) and 45 (\$/hour) $\leq c \leq 180$ (\$/hour), we have: 


$$
h_{2}(v)=\left\{\begin{array}{cc}
4.48 \times 10^{-5}\left[5 v-2.25+(1.8+v) \ln \left(\frac{0.45}{v}\right)\right] & \$ 0.45 \leq v \leq \$ 1.8 \\
4.48 \times 10^{-5}[3 v+1.35-1.39(1.8+v)] & \$ 1.8 \leq v \leq \$ 33.75 \\
4.48 \times 10^{-5}\left[136.8-1.01 v+(1.8+v) \ln \left(\frac{v}{135}\right)\right] & \$ 33.75 \leq v \leq \$ 135
\end{array}\right.
$$

Where 0.75 (hrs.) $\leq t \leq 5$ (hrs.) and 1 (\$/hour) $\leq c \leq 45$ (\$/hour), we have:

$$
h_{3}(v)=\left\{\begin{array}{cc}
2.39 \times 10^{-5}\left[7.67 v-5.75+(5+v) \ln \left(\frac{0.75}{v}\right)\right] & \$ 0.75 \leq v \leq \$ 5 \\
2.39 \times 10^{-5}[5.67 v+4.25-1.9(5+v)] & \$ 5 \leq v \leq \$ 33.75 \\
2.39 \times 10^{-5}\left[230-1.02 v+(5+v) \ln \left(\frac{v}{225}\right)\right] & \$ 33.75 \leq v \leq \$ 225
\end{array}\right.
$$

Where 0.75 (hrs.) $\leq t \leq 5$ (hrs.) and 45 (\$/hour) $\leq c \leq 180$ (\$/hour), we have:

$$
h_{4}(v)=\left\{\begin{array}{cc}
7.81 \times 10^{-6}\left[360-10.67 v+(900+v) \ln \left(\frac{v}{33.75}\right)\right] & \$ 33.75 \leq v \leq \$ 135 \\
7.81 \times 10^{-6}[-675-3 v+1.39(900+v)] & \$ 135 \leq v \leq \$ 225 \\
7.81 \times 10^{-6}\left[2(v-900)+(900+v) \ln \left(\frac{900}{v}\right)\right] & \$ 225 \leq v \leq \$ 900
\end{array}\right.
$$

Then, the general formula of $h(v)$ is obtained as follows:

$$
\begin{gathered}
h(v)=\sum_{i=1}^{4} h_{i}(v) I(i) \\
I(i)=\left\{\begin{array}{lc}
1 & \text { if } v \text { is maped by } h_{i}(v) \text { on segment }\left(v_{k-1}, v_{k}\right) \\
0 & \text { otherwise }
\end{array}\right.
\end{gathered}
$$

Where index $k$ represents different intervals of variable $v$ (Totally, there are 12 intervals). The total labor cost distribution $h(v)$ is a continuous PDF over the interval $\left[v_{\min }, v_{\max }\right.$ ] that in fact is defined as a summation of the sub-functions $h_{i}(v)$ for every single value of $v$. Here, $v_{\min }$ equals $0\left(v_{\min }=t_{\min } \times c_{\min }=0\right)$ and $v_{\max }$ equals $\$ 900\left(v_{\max }=t_{\max } \times c_{\max }=5\right.$ (hrs. $) \times 180(\$ /$ hour $)$ ).

Fig. 5 shows the final pdf for the repair labor cost that is a right-skewed distribution with mean value of $\$ 144(E[v]=E[t] \times E[c])$. The distribution of labor costs can help consumers make a decision on whether to repair or replace a product. Suppose that buying a new product, e.g. a smart phone, costs $\$ 600$, and a consumer wants to decide between repairing the broken smart phone and buying a new one. What is the probability that the labor cost will be less than a specific amount, e.g. \$200? Fig. 6 shows these probabilities and also the ratio of the repair labor cost to the price of a new smart phone. To give an example, there is a 0.76 chance that the labor cost is less than $\$ 200$. To get the total repair cost, we also need to add the cost of spare parts that are used in the repair process that highly depends on the type of product. Therefore, the estimated labor cost is a lower bound for the total repair cost.

Again, it should be noted that the repair technicians estimated the repair time for all types of consumer electronics. It is very hard to capture the average repair time spent on repairing a specific type of electronic devices, unless some experiments are carried out to measure the repair time. It is assumed that the labor cost per unit of time is less dependent on the type of devices. On the other hand, the cost of spare parts would be different for the consumer electronics. Therefore, the total cost of repair services of consumer electronics is more related to the cost of spare parts rather than the labor cost. 
According to the findings of this section, the likelihood of the retirement and replacement decision of an old device is related to the original market price of the new device. Therefore, many electronic devices such as computer gadgets are discarded early, since new tech products are offered at an affordable price. Hence, the different types of consumer electronics can be classified based on the risk that they may not be repaired just after the first observed failure.

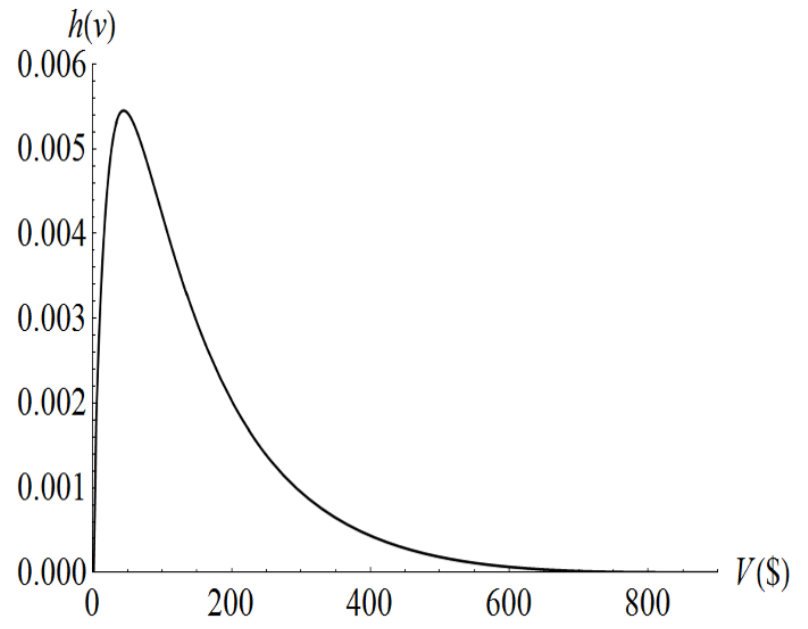

Fig. 5 The probability density function for the total repair labor cost.

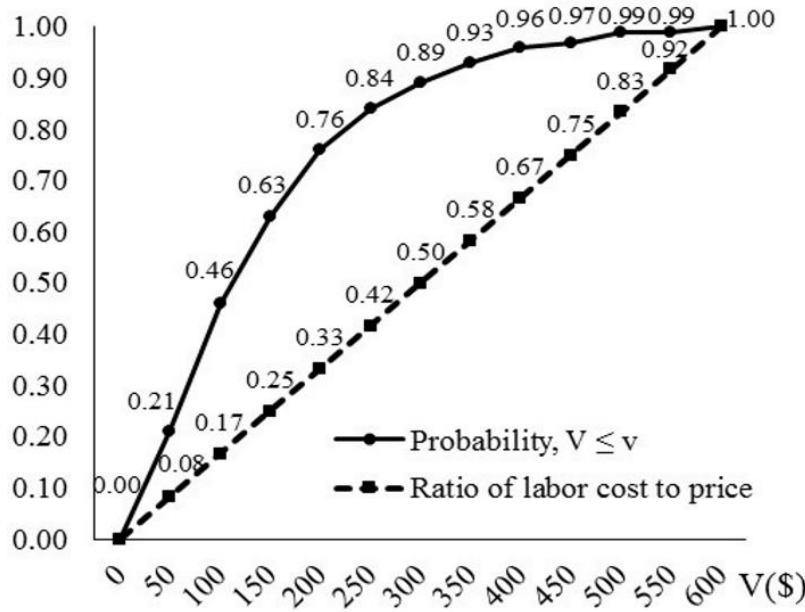

Fig. 6 A comparison between the repair labor cost and replacement cost.

\subsection{Demand-based Repair Service Pricing Model}

The consumers' willingness to repair a broken product is mainly influenced by the repair cost, although other factors such as the socio-demographic characteristics and product attributes, can also impact their decisions (For more information see [17]). A question rises as what is the market demand for repairing electronics in the US. To answer this question. McCollough [2] used the number of employees in the repair shops as a representative of the market demand for electronics. He found that the number of employed repair technicians is negatively correlated to the ratio of repair cost to the replacement price, and positively correlated to Gross Domestic Product (GDP) growth rate. The repair infrastructures (e.g. the number of repair shops) and consumers' repair propensity are interrelated in a positive feedback loop. Therefore, the accessibility to the repair infrastructures increases the consumers' repair propensity. The second question is 'what is the optimal pricing policy that repair shops should adopt given the existing repair demand?' We follow the demand modeling approach introduced in [2] to create a demand-based repair service pricing model. Let's assume that the per-time-unit labor cost $c_{l}$ is a decision variable to control the repair propensity. $T, c_{r}$, and $P_{n e w}$ represent the average repair time, the cost of spare parts, and the price of a new product, respectively. $S$ shows the salvage price for the broken product. Finally, $b_{1} \leq 0$ and $b_{2} \geq 0$ are two coefficients represent the impact of the contributed factors. Table 2 contains the parameters, variables, and functions with their definitions. The probability that a consumer wants to repair a broken product $P_{r}$ is quantified by Eq. 9. According to this equation, if the hourly repair charge $\left(c_{l}\right)$ is higher than a specific amount, then there is zero chance that the consumers choose repair option. On the other hand, the consumers always choose repair option if the value of $c_{l}$ is sufficiently low. 


$$
P_{r}=\left\{\begin{array}{cc}
1 & \text { if } c_{l} \leq-\frac{b_{2} \cdot G D P .\left(P_{\text {New }}-S\right)+b_{1} c_{r}}{b_{1} T} \\
0 & \text { if } c_{l} \geq-\frac{\left(b_{2} \cdot G D P+1\right) \cdot\left(P_{\text {New }}-S\right)+b_{1} c_{r}}{b_{1} T} \\
\left(1+b_{1} \cdot \frac{c_{l} T+c_{r}}{P_{\text {New }}-S}+b_{2} \cdot G D P\right) & \text { otherwise }
\end{array}\right.
$$

Table 2 The nomenclature table.

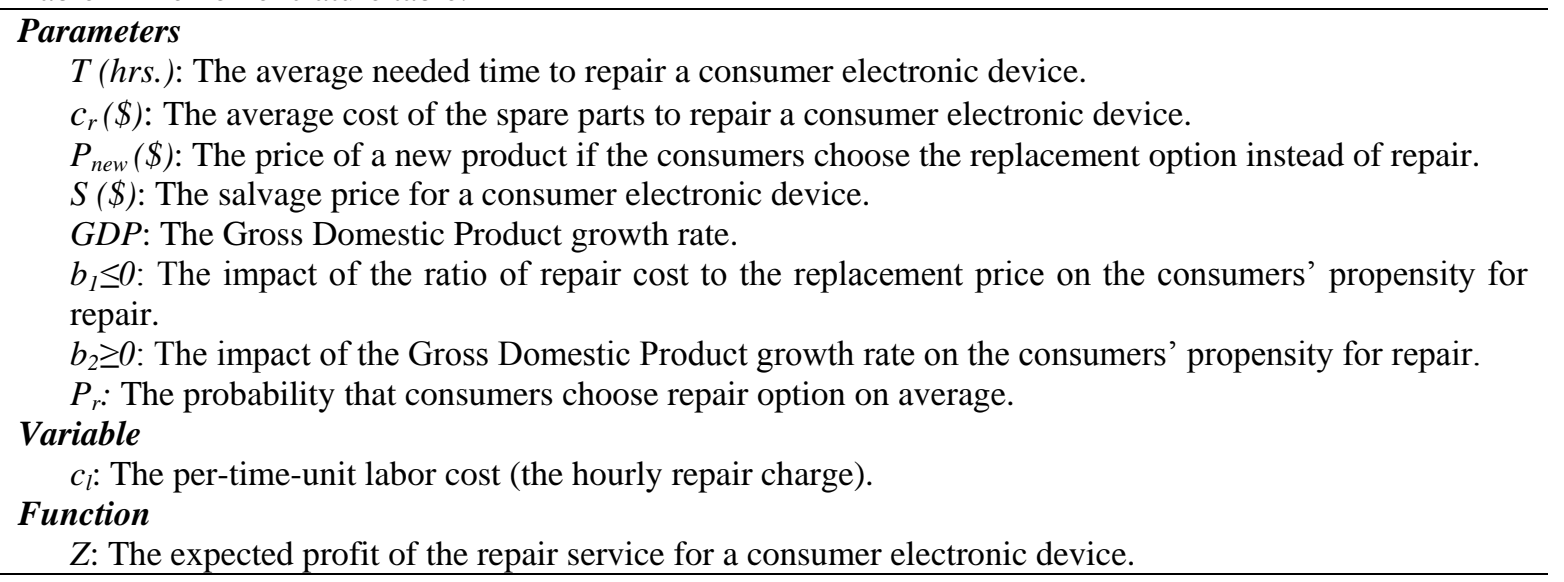

If $c_{l} \cdot T$ is the expected profit of the repair service for a product (Assume that repair operation cost is a constant value), then the pricing problem to determine the optimum hourly labor cost $\left(c_{l}\right)$ can be modeled as follows:

$$
\begin{aligned}
& \underset{c_{l}>0}{\operatorname{Maximize}} Z=c_{l} \cdot T \cdot P_{r} \\
& \text { s.t. } \\
& 0 \leq c_{l} \leq \frac{P_{\text {New }}-S-c_{r}}{T}
\end{aligned}
$$

The upper bound in the constraint indicates that consumers normally prefer that the repair cost would be less than the replacement cost. The optimal solutions for the per-time-unit labor cost $\left(c_{l}\right)$ are summarized in Table 3.

Table 3 The optimal values for the per-time-unit labor cost with associated feasible range.

\begin{tabular}{cl}
\hline Optimal per-time-unit labor cost $c_{l}^{*}$ & Feasible range \\
\hline \hline$-\frac{\left(P_{\text {New }}-S\right)\left(1+b_{2} \cdot G D P\right)}{2 b_{1} T}-\frac{c_{r}}{2 T}$ & $\left\{b_{1} \leq-b_{2} \cdot G D P \cap\left(P_{\text {New }}-S\right)\left(1+b_{2} \cdot G D P\right) \geq b_{1}\left(2 P_{\text {New }}-2 S-3 c_{r}\right)\right.$ \\
$\frac{P_{N e w}-S-c_{r}}{T}$ & $\left\{b_{1}>-b_{2} . G D P\right\} \cup\left\{b_{1} \leq-b_{2} \cdot G D P \cap\left(P_{N e w}-S\right)\left(1+b_{2} \cdot G D P\right)<\right.$ \\
& $\left.b_{1}\left(2 P_{\text {New }}-2 S-3 c_{r}\right) \cap\left(P_{\text {New }}-S\right)\left(1+b_{2} . G D P\right) \leq-b_{1} c_{r}\right\}$
\end{tabular}

The results of this section can be applied by repair businesses to maximize the expected profit of the repair services by considering the consumers' sensitivity to the repair cost. As an extension of this model, repairers can determine the optimal amount of discount on the repair labor cost and evaluate the impact of the discount on the future trend of demand for repair services. Furthermore, it is assumed that repair businesses most likely have not been influenced by the labor availability. Otherwise, the fluctuations in the labor market should be considered in pricing repair services [39]. 


\subsection{The Effect of Spare Parts Supply Strategy}

To provide better insights, a numerical example with a sensitivity analysis is provided. Consider the smart phone example, the baseline values for $b_{1}, b_{2}, c_{r}, T, P_{n e w}, S, G D P$ are set to be $-2.1,0.16, \$ 100,2 \mathrm{hrs}$, $\$ 600, \$ 150$, and $2.4 \%$, respectively. The optimal value of $c_{r}{ }^{*}$ and the expected profit are $\$ 49.14$ and $\$ 45.08$, respectively. To see the effect of parameters on the optimal values, a sensitivity analysis is done for the impact of the cost of spare parts (Fig. 7). Any increase in the cost of spare parts will decrease both optimal values.

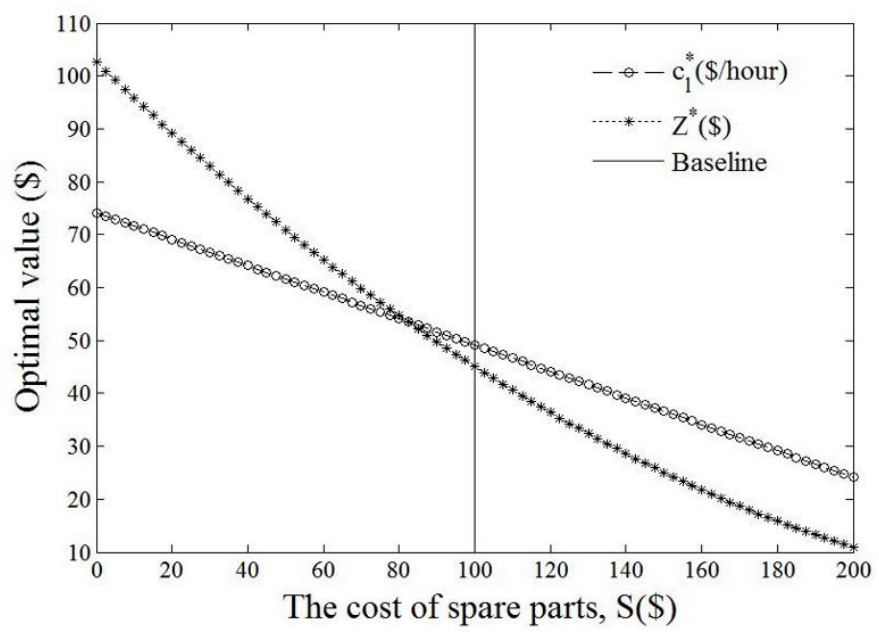

Fig. 7 The variation in the optimal values of per-timeunit labor cost, $c_{l}^{*}(\$ /$ hour $)$ and expected repair profit $Z^{*}(\$)$ based on the changes in the cost of spare parts, $S(\$)$.

This parameter together with the product price is controlled by manufactures. In addition, the manufacturers' adopted design policies may result in consumers' unwillingness to repair the broken products. In the case of modular-designed products, repair processes are facilitated by detaching only the failed module. The products are no longer as modular as they were before (e.g., the battery is glued and adhered to the case in some smart phones). Then, there might be a situation that the repair technicians have to replace even non-failed parts since they are strongly attached to the failed part. The salvage value is determined by the trade-in programs, recyclers, and refurbishers in the second-hand market. Likewise, if they offer higher prices, then the consumers prefer to sell the old products in the second-hand market rather than keeping the obsolete products in storage.

The way that the supply of spare parts is managed may advantageously or unfavorably impact not only independent repair businesses but also manufacturers. Therefore, the companies cautiously select the spare parts provider. The respondents who work for the IT departments answer the question of "What does your organization look for most in a parts supply company?" and asked to rank the six important factors. Part (a) of Fig. 8 shows the variation of the ranks selected by the respondents. For example, most of respondents highly ranked the price, while a few respondents rank it lower. As it could be predicted, the price and quality of the products highly matter to the companies when choosing the suppliers. The customer services is counted as the third important factor compared to the other factors such as shipping time, return policy, and previous business relationship (Fig. 8 (b)).

The effective repair and maintenance of the machines and equipment are of great importance to control the yield of the production and operation systems. In addition to the labor cost, the cost of the 
spare parts might be the only important factor for the most of non-professional users to make the repair decision. However, we see that other factors such as shipping time and return policy are also considered by companies to select suppliers of spare parts and repair providers. Thus, the cost of spare parts should be re-formulated in the repair service provider-customer relationships modelling.

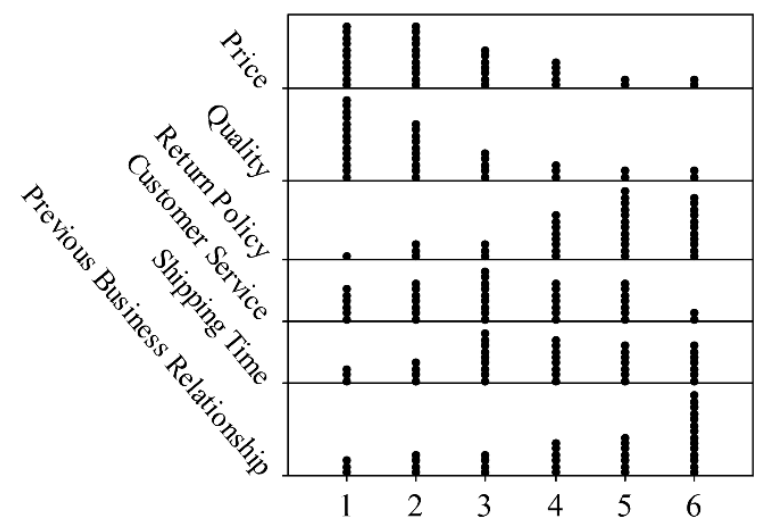

(a) Rank of Criteria for Supply Company Selection

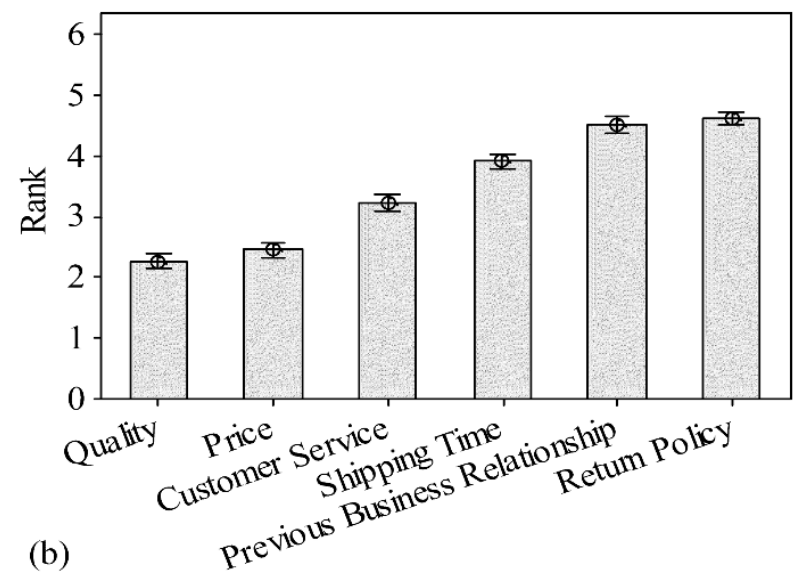

(b)

Fig. 8 (a) the importance of decision factors for selection of a part supply company. (b) The $95 \%$ confidence interval for the rank of decision factors.

\section{Technical Challenges Facing Repair Businesses}

In the previous section, the quantified repair cost was introduced as a main barrier to repair the obsolete consumer electronics. However, there are other problems that make the repair processes hard or impossible for repairers such that they may even suggest consumers to buy a new device instead of repairing it. In this section, the consumer electronics are clustered based on a set of difficulties in repairing the devices. These difficulties are merely associated with the design of the product, repair tools, the supply chain management of spare parts, and manufacturers' policies to share the repair instructions. Due to the lack of strong intellectual property rights, such restrictive policies are basically adopted by the OEMs to raise the cost of remanufacturing for competitors [40].

After conducting the clustering analyses on the repair difficulties, the respondents' opinions about the repair formal training and self-directed learning processes, and the design of the repair instruments are surveyed to see how the repair industry can be further promoted besides improving other factors such as the product design and the supply of spare parts.

Repair businesses are faced by several operational and logistical challenges. For example, the repair experts often complain about the lack of repair guidelines. The repair actions are sometimes taken based on conjecture, since the repair information is partially available or completely inaccessible even among the products of a single manufacturer. The uncertain time of diagnosing the exact failure may influence the profitability of repair businesses. To clarify this point, if the defects are not efficiently diagnosable, then repairmen have to repeat the disassembly and reassembly processes (even if a smart troubleshooting system is employed) several times which results in higher labor costs. Sometime, even the customers' explanation about the failure are not helpful in explaining what the exact problems are.

After faults detection, repair technicians may be faced with new challenges. First, the devices need to be opened. The technicians face proprietary design of parts, e.g. size screws with special forms and sizes. Then, the spare parts must be found if the old component replacement is required. A difficulty arises if the spare parts are no longer provided by the original equipment manufacturer (OEM); repair technicians may have to find a used but still functional component or avoid the repair work. In addition, the reassembly 
process is affected since the parts may be made to different tolerances. Fig. 9 shows different steps of a typical repair process.

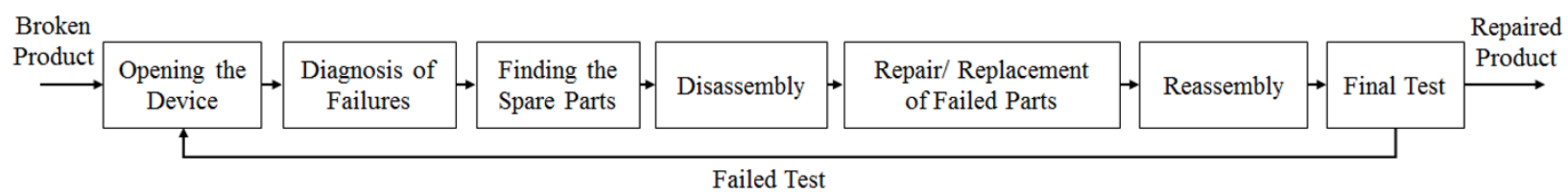

Fig. 9 The different steps of a typical repair process.

\subsection{Clustering of Consumer Electronics based on Difficulties in Repair Processes}

The product structure and the way that components are put together inside a product may also result in more failures throughout the repair process. If the failed component is not easily accessible or adhered to other components, then detaching the component may damage the connectors or other parts. Generally, repairing the first generation of a product family is harder than the subsequent generations. In addition, the repair processes may include some safety risks due to either incautious actions taken by repairmen or lack of safety notification provided by OEMs.796 repair practitioners answered the following questions:

- 'What was the last thing you tried to fix and did not succeed (or clients were no longer interested in repairing)?'

- 'Why did you not succeed in fixing it?'

Fig. 10 shows the most common products (the number of observations is written in the parentheses) and the associated reasons behind an unsuccessful repair.

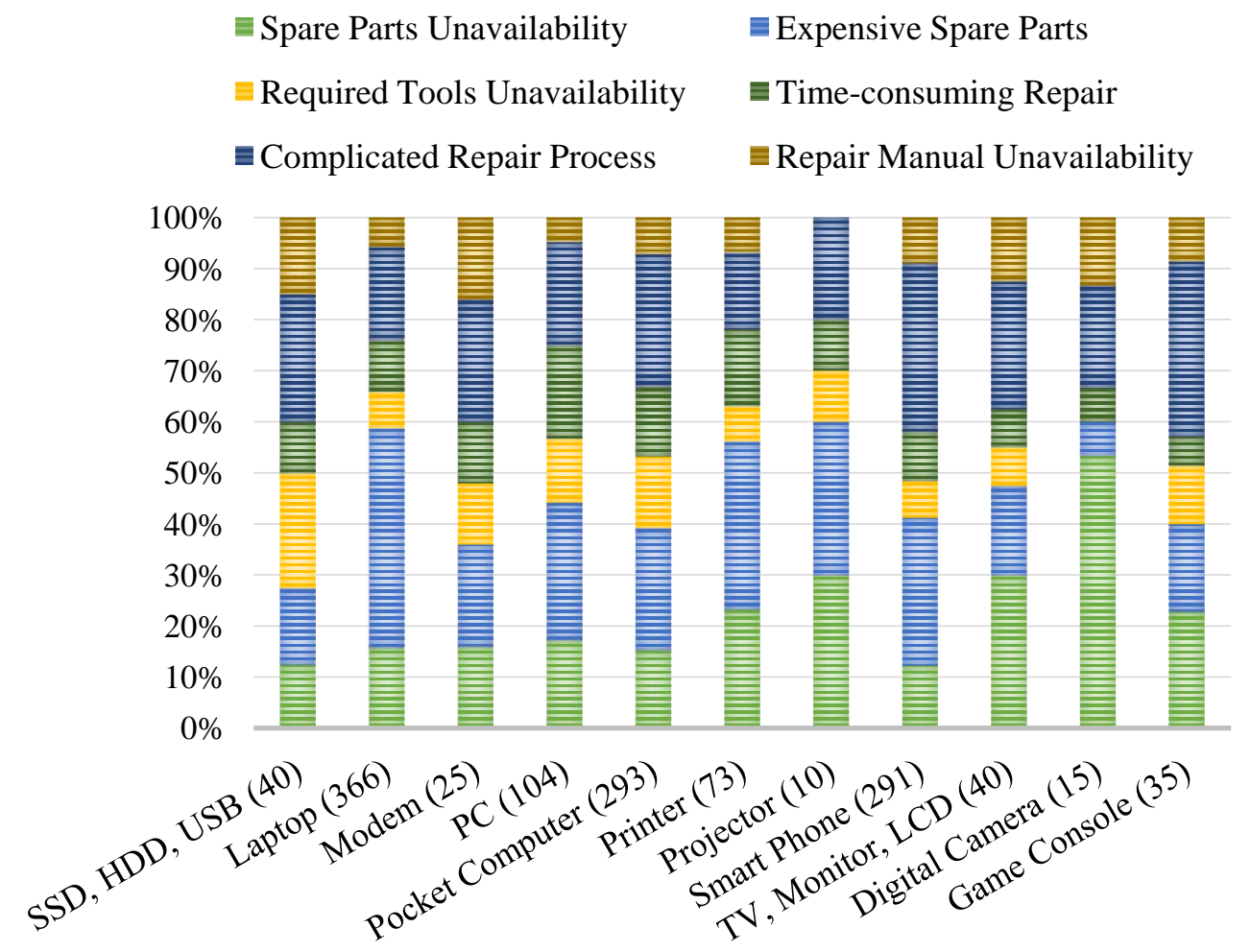

Fig. 10 The most common products that repair businesses could not repair them together with the reasons. 
We use $K$-means, a widely-used method of clustering, to cluster each type of device based on the reason it was not repaired. According to this method, similar objects are grouped applying an iterative algorithm to minimize the cost function $G$ which is the sum of squared errors between the centroid values of each group and objects' data point [41]. A Euclidean formula has been used to calculate the distances. Assume that the set of objects is defined as $X=\left\{x_{i}, i=1, \ldots, N\right\}$ and $\mu_{j}$ represents the center of cluster $k_{j}$, $j=1, \ldots, K$. Then, the function $G$ is defined as:

$$
G=\sum_{i=1}^{N} \sum_{j=1}^{K} \alpha_{i j}\left\|x_{i}-\mu_{j}\right\|^{2}
$$

Where $\alpha_{i j}$ is 1 if the object $x_{i}$ is assigned to the cluster $k_{j}$. This algorithm starts with initially $K$ centroids and updates them based on the newly added objects until the value of function $G$ reaches the pre-specified threshold and stops the reassignment process of objects. Before doing so, however, we need to check the multicollinearity of variables. No multicollinearity issue detected through using the zero-order correlations and variance inflation factors. The correlation values range from -0.69 to 0.45 (no significant correlation is found at $\alpha=0.01$ ) and variance inflation factors range from 1.05 to 1.89. Fig. 11 represents the relationships between each pair of the reasons for unsuccessful repairs. There are fifteen sub-plots of the six reasons. In Fig. 11, scatterplots also show that the relationships between the reasons for the unsuccessful repair processes are relatively weak. The $R^{2}$ of the best fitted regression line is 46.9 that is not considerable for a meaningful relationship. The time-consuming repair process and complicated repair process were hypothesized to be correlated, but no correlation is found. There might be a situation, in which the repair process is time-consuming itself but is straightforward (e.g., when the parts are superglued together). On the other hand, a repair task may take a short time as long as a repair technician could figure out how to repair it that depends on the level of repair expertise.

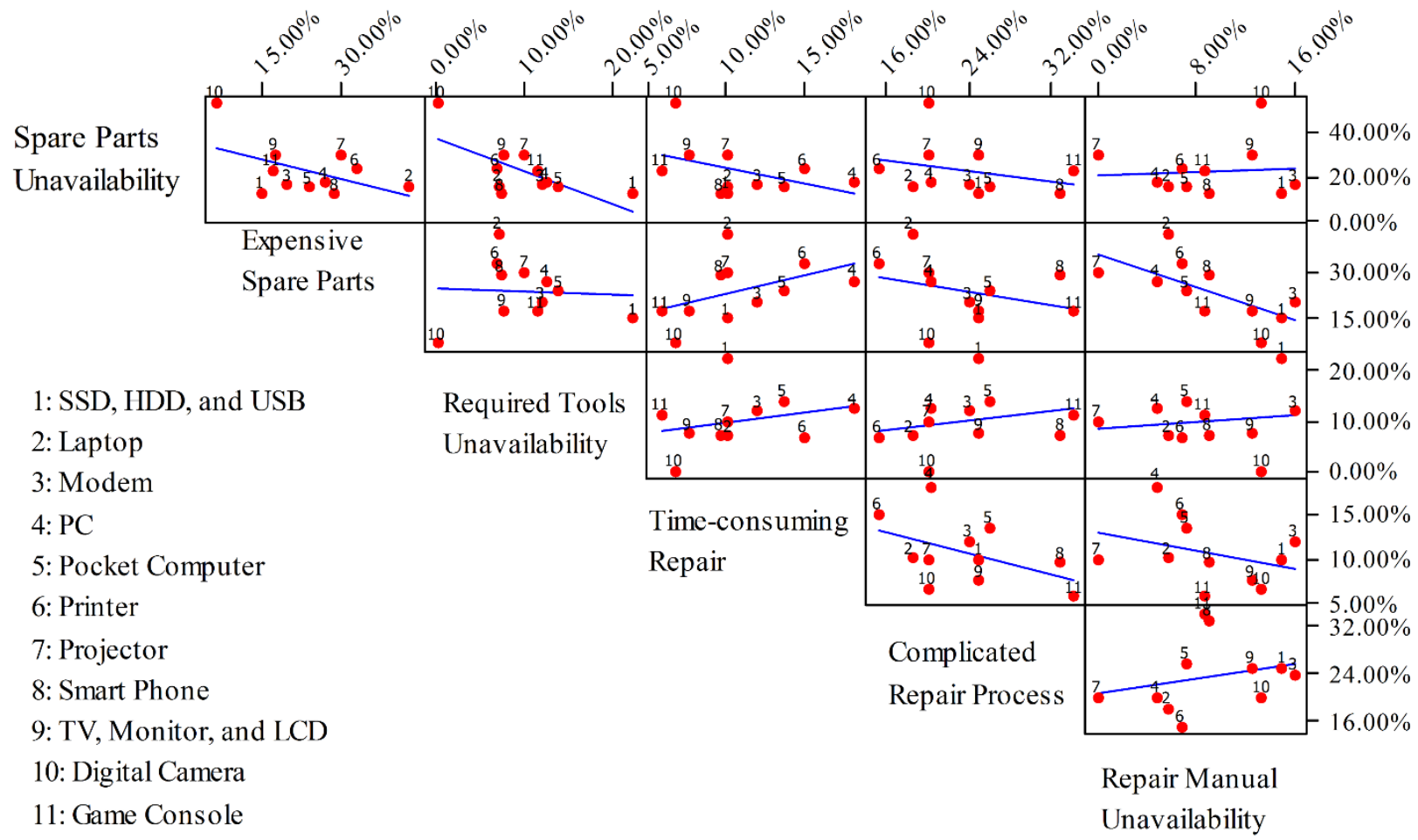


Fig. 11 The scatterplots demonstrate the relationship between the reasons for the unsuccessful repair processes.

Table 4 shows the result of $K$-means algorithm. We see that the percentages of reasons are relatively homogeneous for the set of products in the first cluster. However, their complicated repair process is ranked first. Laptops are the only consumer electronics in the second cluster. Although they are very similar to the devices in the last cluster in terms of technology, the repair technicians believe that the cost of spare parts replacement is the main reason that dissuades consumers from getting their products fixed. Their repair process is complicated as well. The products in the third clusters are generally more durable than the other consumer electronics and consumers use them for a longer time. As a consequence, the repair shops receive relatively-old products, e.g. televisions that their spare parts are not available in the market. Similar to the laptops, the repair of products in the last cluster suffers from expensive spare parts but more complexity.

Table 4 The clustering results of consumer electronics based on the reasons for their unsuccessful repair processes.

\begin{tabular}{lcccc}
\hline & Cluster 1 & Cluster 2 & Cluster 3 & Cluster 4 \\
\hline & $\begin{array}{c}\text { Solid Sate Drive, Hard } \\
\text { Disk Drive, USB, and } \\
\text { Modem }\end{array}$ & Laptop & $\begin{array}{c}\text { TV, Monitor, LCD, } \\
\text { Digital Camera, } \\
\text { and Game Console }\end{array}$ & $\begin{array}{c}\text { PC, Pocket Computer, } \\
\text { Smart Phone, Printer, } \\
\text { and Projector }\end{array}$ \\
\hline Spare Parts Unavailability & $14 \%$ & $16 \%$ & $35 \%$ & $20 \%$ \\
Expensive Spare Parts & $18 \%$ & $43 \%$ & $14 \%$ & $28 \%$ \\
Required Tools Unavailability & $17 \%$ & $7 \%$ & $6 \%$ & $10 \%$ \\
Time-consuming Repair & $11 \%$ & $10 \%$ & $7 \%$ & $13 \%$ \\
Complicated Repair Process & $25 \%$ & $18 \%$ & $26 \%$ & $23 \%$ \\
Repair Manual Unavailability & $15 \%$ & $6 \%$ & $12 \%$ & $6 \%$ \\
\hline
\end{tabular}

\subsection{Repair Workforce Development: Formal Training versus Self-directed Learning}

The outcome of repair operations completely depends on the repair skill-level whether it has been obtained via formal training, self-directed learning, or both. But, which one is the fastest way to raise the repair proficiencies according to the repair businesses' point of view? Does the formal repair training empower them to deal with the repair problems? The repair businesses answered a question of 'whether the certifications give them an edge over the competition or not'.

Reading the repair businesses' opinions provides some insights about the repair skills development and training. Among all repair practitioners who have repair certifications or formal training, 162 respondents formed their own opinions based on what they have experienced. $43 \%$ of the respondents believe that repair certifications and formal training would not be of much advantage, except that consumers trust them more whenever they observe them. In contrast, 29\% of them think that the formal training brings significant proficiency. Some respondents (22\%) remarked that they were helpful but not as much as practical learning, their expertise, and repair skills gleaned over the years of their career. Finally, the rest of the respondents $(6 \%)$ mentioned the beneficial access to the manufacturers' formal services as the main advantage of being certified as a trained repair technician.

The ineffectiveness of formal repair training programs claimed by a large number of respondents might be related to the point that they expect to obtain very detailed information about all brands, instead of general principles and guidelines. However, manufacturers do not usually share the repair information with the public. So, often the formal training programs are offered under terms and conditions dictated by manufacturers. 
Finally, it should be noted that repair technicians are valuable sources of information to ascertain the market demand for remanufactured products, to derive information about the usage behavior of consumers, and to extract insights about the real performance of products over their life cycles [42].

\subsection{Design of Repair Tools}

As explained in Section 5, there is no doubt that the existing products' design is in need of revision. Repairing a product is reclaimed as a certain right of consumers. For example, the Right to Repair Bill (http://righttorepair.org) obliges the automobile firms to fully share the repair instructions with their consumers. However, there are other aspects, e.g. improving the repair tools' design that rarely gets attention. 265 repair practitioners answered the question of 'What problem do you regularly encounter that you wish you had a better tool for?'

The following aspects of the design have been raised by the respondents:

- Materials used in repair tools

- Size of the repair tools

- Multifunctional and flexible tools

- Smart/intelligent tools

- Ergonomic design of repair tools

- Safety issues

From their response, we can infer that the repair tools are not efficiently designed (55\%). For instance, respondents wished tools to have more lasting magnetic grips to hold ferrous objects in place or better screw drivers that do not strip so easily. Appropriate opening tool for fragile cases is another example of the need for more efficient repair tools. Next, they had a desire for having multifunctional and flexible repair tools (20\%). To give some examples, a screw driver with adjustable angle and length for a range of proprietary screws or smaller tools that they can get parts out easily are highly demanded. The repair process is sometimes complicated that they wished they had an intelligent assistant for the troubleshooting and testing processes (10\%). Identifying the obscure parts with an unknown manufacturer is a time-consuming process. So what if a smart system tells the technician the details of the part? Furthermore, keeping track of parts when a technician takes apart a device and screw size smart identifier might be so helpful.

The limitations of technicians and safety issues should be taken into consideration at the repair tools design stage (6\%). Adding safety guards to the repair tools may prevent an injury from happening. Removing the screen from electronics or replacement of failed parts was reported as a prevalent difficulty. Therefore, an automatic tool may help the practitioner (5\%). They also need to know how to use the repair tools properly (3\%). All the above-mentioned needs for better tools are somewhat responded to by the technological progress, but they should be also affordable for most repair shops (1\%). 3D printers would be a useful solution that has not been developed for commercial purposes yet. Table 5 shows the summary of the results. 
Table 5 The Repair tools' design improvement.

\begin{tabular}{lcc}
\hline Possible Solutions & No. & $\%$ \\
\hline \hline Efficient repair tools & 146 & 55 \\
Multifunctional and flexible repair tools & 52 & 20 \\
Intelligent troubleshooting and repair assistant system & 26 & 10 \\
Ergonomic design of repair tools & 16 & 6 \\
Automated repair tools & 13 & 5 \\
Guides for repair tools' usage & 8 & 3 \\
Repair tools' price & 3 & 1 \\
3D printing tools & 1 & 0 \\
\hline
\end{tabular}

To summarize, the results of the clustering analysis can be used to upgrade standards for the product design and facilitate repair processes. In addition, it is found that formal training programs are not as effective as they might be. A main portion of repair skills is obtained via self-learning. Therefore, there is a need for revising the formal training programs. Finally, the ideas about the design of repair instruments can be employed by related manufacturing firms to improve the design and gain a higher market share. It should be noted that the design of repair tools is connected to the way that a product is designed. Hence, there are limitations on what innovative design ideas can be put into practice. However, some improvements in the design of repair tools such as increasing the level of flexibility, multi-functionality, and user-friendliness seem to be possible and independent of the product design.

\section{Consumers' Satisfaction of Repair Services from the Perspective of Repair Businesses}

Why do consumers prefer to fix a broken product instead of getting a new one? And, how does the product repair bring happiness for consumers? 416 respondents answered the question of 'how they have been a repair hero to a customer?' A more accurate way to measure the satisfaction of repair services is to query consumers on their opinions directly. However, the question is designed in such a way that the repair technicians' responses reflect the receiving feedback from their consumers in a real situation. The wording used in most of the responses show that the repair technicians' thoughts about the repair services are merely representative of the consumers' speech.

The most common reasons behind consumers' willingness to repair a product and their satisfaction of repair services have been extracted using a manual data-cleaning process. For example, a repair technician mentioned that 'I recover very important data such as picture of family that was no backed up.' Therefore, it is inferred that the data recovery was the main reason to repair. In another case, a repairman stated that 'I fixed something worth over $\$ 1000$ for the cost of a $\$ 5$ part.' Hence, the fair repair charge was the main motive for repair. To avoid misinterpretation, the ambiguous responses were analyzed precisely to check agreement across the researchers.

In some cases, consumers feel emotional attachment to their products because of the good memories they had, and/or they believe in a higher functionality of their currently owned products compared with the new products in the market. The repair shops report this emotional bond as they have experienced fixing the same product owned by a particular client several times over a relatively short period of time. As a concrete example, assume a kid that insists on repairing a broken toy because he is highly attached to it.

Regarding the importance of personal data, any product that contains a data storage device is also precious for consumers such that consumers even consent to pay more to repair the device. Highly damaged products may seem unrepairable from the viewpoint of the clients at the first look. Assuming a case that a consumer runs over a smart phone with a heavy truck, most likely the external components are 
broken, at least. At the first glance it seems that there is no way to fix it, but there might be a chance that the internal parts are still functional and the embedded value can be reused [43]. If that is the case, repairing the product sounds desirable to the consumer. It brings more credit for the repair shops whenever the product could be fixed by the original manufacturers that offer after-sale services. Receiving high quality repair services is also a motivation for future repair decisions. In addition, consumers would be surprised whenever their products are affordably repaired in a short amount of time.

The results of the manual data-cleaning process (Table 6) show how the product repair would be an attractive choice for consumers. The stories provided in the survey have been categorized under six different scenarios: 1) quality of repair service: consumers mainly worry about the quality of repair services and whether they lose out on the product's functionality (24\%). 2) Cost of repair: It matters to the consumers how much repair shops charge them (21\%). They would rather buy a new product if repairing the current owned product is costly. 3) Data recovery: The personal data is of vital importance that the consumer may prefer to retrieve the data rather than repairing the whole damaged product (20\%). 4) Unbelievable successful repairs (16\%), 5) Short repair time (11\%) and, 6) Emotional attachment to products (8\%): attachment to the products would content consumers to choose the repair option but not as much as the other factors. It should be noticed that the results may change if we inquire of consumers about their desires and opinions as well. Also, the satisfaction factors may seem to have overlap with each other. For example, a consumer who has valuable information in a computer is attached to it. However, we stressed the product design characteristics and consumer's emotional feelings in the definition of consumer-product attachment rather than the importance of data.

To conclude this section, we should note that the satisfaction strongly relates to the consumers' expectation. The factor of time could be a good example to clarify this point. The repair time by itself does not create any extra value for consumers, unless repair services are done much faster than the expected time. Furthermore, the delay in the repair time and its negative impact on the consumer's satisfaction might be moderated if the repair shops offer loaner devices as replacement. This is unusual for the consumer electronics repair industry.

\begin{tabular}{lcc}
\multicolumn{3}{c}{ Table 6 Consumers' satisfaction with the repair service received. } \\
\hline Satisfaction Factor & No. & $\%$ \\
\hline \hline High quality of repair services & 101 & $24 \%$ \\
Fair repair charge & 88 & $21 \%$ \\
Data retrieval & 81 & $20 \%$ \\
Unbelievable successful repair & 66 & $16 \%$ \\
Short repair time & 48 & $11 \%$ \\
Consumer-product attachment & 32 & $8 \%$ \\
\hline & Total: 416 & $100 \%$ \\
\hline
\end{tabular}

\section{Willingness of Repair Businesses to Raise Public Awareness about Repair}

Single repair businesses would benefit from raising the public repair awareness and also sharing the resources and repair knowledge through devoted green initiatives and partnerships. Assuming those profits are realizable, the questions arise here as to how to convince independent repair businesses, governmental agencies, and consumers to be involved, and how to meet every party's expectations. The IT departments and repair businesses were questioned of 'which barriers dissuade them from collaboration and how they would be motivated and enthusiastic about working together'. In fact, the findings of these questions may have implications to form a coalition of all repair businesses. Such a coalition is much effective to promote the repair practices in a community since the interests of different stakeholders are more aligned with one another. In Table 7, the summary of the responses is presented. 
The IT departments and repair businesses stressed the lack of time as the main reason behind their unwillingness for contribution ( $29 \%$ vs. $35 \%$ ). They are partly confused about how to contribute (17\% vs. $17 \%$ ). There should be a mechanism for involving the repair practitioners, e.g. developing a cloud service system that the repair information can be shared or the spare parts can be traded. The technicians who are hired by a company are completely banned from disclosing the information. This is why they do not feel comfortable contributing (24\%). It seems that a relatively large number of respondents suffer from a lack of confidence (15\% vs. 13\%). It may arise as a result of encountering repair difficulties. A group of respondents believe that there is no need for their contribution, despite all the shortcomings in this area (9\% vs. $11 \%$ ). Some respondents worry about the outcomes of partnership (5\% vs. 8\%), e.g. making an inaccurate decision and being penalized. The rest of them stated that they have a limited access to the communication tools such as the internet (1\% vs. 1\%). Finally, no evidence exists for the association between the reasons behind unwillingness for contribution to raise public repair awareness and the type of repair departments $\left(\chi^{2}=3.675, p\right.$-value $\left.=0.721\right)$.

So 'what motivates them to make a significant contribution to the repair initiatives and partnerships?' The IT departments and repair businesses need to make sure that their efforts are beneficial to the public (32\% vs. 32\%). For instance, they want to see how many people use their repair manuals. A flexible collaboration platform would encourage them to participate as much as they can (28\% vs. $30 \%)$. The rest of the respondents may just be persuaded by being paid (22\% vs. 19\%) or advertised for their efforts (18\% vs. 19\%). Both IT departments and repair businesses have almost the same opinion about the importance of motivational factors for contribution to raise the public repair $\left(\chi^{2}=0.316, p\right.$-value $\left.=0.957\right)$.

Table 7 The summary of IT departments and repair businesses' opinions about contribution to raise public repair awareness and collaborative partnerships.

\begin{tabular}{lcccc}
\hline & \multicolumn{2}{c}{ IT departments } & \multicolumn{2}{c}{ Repair businesses } \\
\hline $\begin{array}{l}\text { The reasons behind unwillingness for contribution to } \\
\text { raise public repair awareness }\end{array}$ & No. & $\%$ & No. & $\%$ \\
\hline \hline I do not have enough time to contribute & 276 & 29 & 213 & 35 \\
I do not know how to contribute & 161 & 17 & 104 & 17 \\
I do not feel comfortable to contribute & 236 & 24 & 94 & 15 \\
I feel diffidence about my own repair abilities & 145 & 15 & 83 & 13 \\
There is no need for my contribution & 90 & 9 & 64 & 11 \\
I am afraid of making a mistake and getting in trouble & 49 & 5 & 47 & 8 \\
Lack of interaction on internet & 7 & 1 & 4 & 1 \\
\hline & Total: 964 & 100 & Total: 609 & 100 \\
\hline The motivation factors for contribution to raise public & \multirow{2}{*}{ No. } & $\%$ & \multirow{2}{*}{ No. } & $\%$ \\
repair awareness & 91 & 32 & 114 & 32 \\
Assuring that public would benefit & 79 & 28 & 107 & 30 \\
I contribute as much as I can & 61 & 22 & 67 & 19 \\
Incentive Compensation & 51 & 18 & 67 & 19 \\
Advertisement & Total: 282 & 100 & Total: 355 & 100 \\
\hline
\end{tabular}

\section{Business Lessons Learned by Repair Service Providers}

Given all the previous points, how can repair businesses be promoted? The responses to the question of 'What has been your biggest business mistake or most helpful lesson learned?' are also reviewed to capture some insights about how the performance of repair businesses should be improved.

One challenge discussed by the respondents was the point that they have to quote an estimated price for their repair services before the costs of repair were actually known (20\%). The costs are usually under/overestimated because of the uncertain repair duration, workload, and the required number of part 
replacements. It definitely brings dissatisfaction for customers. Therefore, a relatively accurate estimation of repair costs assures customers that they will not be overcharged. Although, it is very hard to gauge the costs only by looking at the outside of a broken device, in some cases, they highly rely on their repair capabilities and never look at the available repair instructions or precautions that may result in reworking (19\%). Inaccurate repair time estimation is also counted as one of the most common mistakes (12\%). If they take on many jobs and give customers a commitment as to the completion date but do not finish them by the due dates, then their reputation will be affected.

The repair businesses need to focus on the voice of customers (11\%). In addition, they should make sure that the clients' expectations should be set beforehand. It needs a certain degree of competence to come to the point that something is not worth fixing. Otherwise, it might be a waste of time taking on torturous repairs. The repair businesses stock a wide range of spare parts to avoid inventory shortage $(9 \%)$. Buying parts from the untrusty suppliers and overstocking are other problems in this matter.

They should make clients aware of the possible outcomes (9\%). If they overpromise, they may get in trouble with unmet expectations. Spending on frightful advertisements can bring more customers to repair businesses (4\%). They reported that the word of mouth, local advertisement, internet advertisement, and cooperation with the retail electronics shops were the most effective marketing methods, respectively to get their first fifty customers. They also answered the questions that 'How did you get your first fifty customers and how do you continue to grow your business?' Apparently, the word of mouth and local advertisement are the best valuable forms of marketing for these small businesses at the early stages of development. The other forms of marketing may be appropriate whenever the repair businesses are firmly stablished.

Some respondents emphasized on hiring more qualified employees and being better staffed for the holiday seasons $(3 \%)$. Clients have concern about their data. Backing up the data is a solution to accidental loss of data (2\%). Finally, the more technicians know the causes and prevention of occupational health problems, the more successful their business will be (1\%). In Table 8, the summary of findings is presented.

Table 8 Restoration of repair businesses- key points.

\begin{tabular}{lcc}
\hline Important aspects of a repair business that should be taken into consideration & No. & $\%$ \\
\hline \hline Repair service pricing and business accounting system & 76 & 20 \\
Repair instructions, precautions, and tools & 71 & 19 \\
Repair time estimation & 44 & 12 \\
Meeting consumers' expectations & 40 & 11 \\
Replacement/ fix decision & 38 & 10 \\
Spare parts inventory management & 35 & 9 \\
Consumers' awareness of outcomes & 34 & 9 \\
Adopting the marketing policy & 17 & 4 \\
Human resource management & 13 & 3 \\
Personal data preservation & 7 & 2 \\
Repair safety and occupational health & 4 & 1 \\
\hline
\end{tabular}

The business model of the current consumer electronics repair industry needs to be revised. According to the lessons extracted from the responses, the structure and operations of the repair businesses should be redesigned and standardized. In Table 8, different aspects of a repair business are sorted based on the number of responses. Therefore, the efforts to re-develop the repair business model should be focused on these aspects according to their priorities. 


\section{Conclusion}

In this paper, an overview of the current status of the consumer electronics' repair industry in the US has been discussed using a survey analysis. 2170 repair technicians participated in the survey and answered all or part of 23 questions about different aspects of the repair industry. In comparison to the literature, this paper deepens the insights about the consumer electronics repair business from the economic, technical, and social aspects. In economic analyses part, the uncertainty in the repair labor cost is captured and represented by a statistical distribution. This distribution is found empirically by using the responses provided by the repair technicians about the time and their expectation of the per-time-unit labor cost. Next, a demand-based repair service pricing model is developed and the optimal values of the per-time-unit labor cost and repair service profit are suggested together with a sensitivity analysis on the cost of the spare parts. In technical part, different types of the consumer electronics are clustered based on the difficulties confronted in their repair processes. Furthermore, the repairers' opinions about the available formal repair training programs and repair instruments are surveyed to provide more insights on the technical aspect. Finally, the social role of the independent repair industry to raise the public awareness, and promote repair practices among a community has been discussed.

The study discussed the changes that the repair industries undergo. The end-users are becoming more interested in repairing the broken products personally. Furthermore, the number of repair technicians who prefer to repair the products at their home is growing faster. It is explained why people have less willingness to repair the low-priced products through quantifying the repair cost. The prevalent repair challenges that the repair technicians face during the repair process are discussed. The consumer electronics have been clustered based on the reasons behind the unsuccessful repair experiences of respondents. Other repair challenges such as meeting the consumers' expectations of repair services and repair workforce development have been discussed to arrest attention of all stakeholders, e.g. repair shops, regulators, and manufacturers, to facilitate the repair operations.

As a limitation of this study, sufficient details on the repair processes and common failures of every single product were not available. This information is helpful to put the objectives and constraints of stakeholders into effect practically and propose effective solutions. The collected data was biased in the sense that the respondents somehow have used the services provided by iFixit.com. Furthermore, every individual did not respond to every question. Thus, the results may be biased by non-responders. All individuals surveyed were repair technicians. The revealed insights about the consumers' preferences for the repair services were from the perspective of repair technicians that might be different from the consumers' viewpoint.

For future studies, all concerns from the stakeholder groups should be incorporated into an integrated strategic decision-making model, to drive decisions that pave the way toward development of a circular economy. The consumers' repair demand and repair infrastructures are interrelated as a part of a whole system. A consumer may have propensity for repair but does not have enough access to the repair shops. On the other hand, there should be a sufficient repair demand to establish a repair shop in a particular region. How they can reinforce each other can be investigated using simulation models such as system dynamics and agent-based models.

Deciding on the level of repair for a specific design depends on the repair outcomes. In some cases, it is better to replace the whole part with a new one instead of repairing. The uncertainties with the repair time, cost, and quality are the factors that determine the repair decision path. 


\section{Acknowledgements}

The authors would like to express their sincere gratitude to Kyle Wiens and the rest of iFixit.com team for sharing the dataset and their invaluable comments on the paper. This material is based upon work supported by the National Science Foundation - USA under grant \# CMMI-1435908. Any opinions, findings, and conclusions or recommendations expressed in this material are those of the authors and do not necessarily reflect the views of the National Science Foundation.

\section{References}

[1] J. Cox, S. Griffith, S. Giorgi, and G. King, "Consumer understanding of product lifetimes," Resour. Conserv. Recycl., vol. 79, no. 0, pp. 21-29, Oct. 2013.

[2] J. McCollough, "Factors impacting the demand for repair services of household products: The disappearing repair trades and the throwaway society," Int. J. Consum. Stud., vol. 33, no. 6, pp. 619-626, 2009.

[3] M. Sabbaghi, B. Esmaeilian, W. Cade, K. Wiens, and S. Behdad, "Business outcomes of product repairability: A survey-based study of consumer repair experiences," Resour. Conserv. Recycl., vol. 109, pp. 114-122, May 2016.

[4] T. Cooper, "Durable consumption: reflections on product life cycles and the throwaway society," in Proc. of Lifecycle Approaches to Sustainable Consumption Workshop, 2002, pp. 11-27.

[5] S. Wei, D. Cheng, E. Sundin, and O. Tang, "Motives and barriers of the remanufacturing industry in China," J. Clean. Prod., vol. 94, pp. 340-351, May 2015.

[6] R. Kahhat and E. Williams, "Materials flow analysis of e-waste: Domestic flows and exports of used computers from the United States," Resour. Conserv. Recycl., vol. 67, pp. 67-74, 2012.

[7] F. Wang, J. Huisman, C. E. M. Meskers, M. Schluep, A. Stevels, and C. Hagelüken, "The Best-of2-Worlds philosophy: Developing local dismantling and global infrastructure network for sustainable e-waste treatment in emerging economies," Waste Manag., vol. 32, no. 11, pp. 21342146, Nov. 2012.

[8] J. Warner, "Understanding cyber-crime in Ghana: A view from below," Int. J. cyber Criminol., vol. 5, no. 1, p. 736, 2011.

[9] T. G. Field Jr, "IP Basics: Trademarks and Business Goodwill,” 2015.

[10] N. Milovantseva and C. Fitzpatrick, "Barriers to electronics reuse of transboundary e-waste shipment regulations: An evaluation based on industry experiences," Resour. Conserv. Recycl., vol. 102, pp. 170-177, 2015.

[11] M.-Y. Chang, K. Chen, C. Pang, C.-M. Chen, and D. C. Yen, "A study on the effects of service convenience and service quality on maintenance revisit intentions," Comput. Stand. Interfaces, vol. 35, no. 2, pp. 187-194, 2013.

[12] S. Boon-Long and W. Wongsurawat, "Social media marketing evaluation using social network comments as an indicator for identifying consumer purchasing decision effectiveness," J. Direct, Data Digit. Mark. Pract., vol. 17, no. 2, pp. 130-149, 2015. 
[13] J. A. Estrada-Ayub and R. Kahhat, "Decision factors for e-waste in Northern Mexico: To waste or trade," Resour. Conserv. Recycl., vol. 86, pp. 93-106, 2014.

[14] D. K. Rosner, "Making citizens, reassembling devices: on gender and the development of contemporary public sites of repair in Northern California," Public Cult., vol. 26, no. 1 72, pp. 5177, 2014.

[15] P. Ghisellini, C. Cialani, and S. Ulgiati, "A review on circular economy: the expected transition to a balanced interplay of environmental and economic systems," J. Clean. Prod., 2015.

[16] D. K. Rosner and F. Turner, "Theaters of Alternative Industry: Hobbyist Repair Collectives and the Legacy of the 1960s American Counterculture," in Design Thinking Research, Springer, 2015, pp. 59-69.

[17] K. A. Scott and S. T. Weaver, "To Repair or Not to Repair: What is the Motivation?," J. Res. Consum., no. 26, p. 1, 2014.

[18] R. Kissling, C. Fitzpatrick, H. Boeni, C. Luepschen, S. Andrew, and J. Dickenson, "Definition of generic re-use operating models for electrical and electronic equipment," Resour. Conserv. Recycl., vol. 65, pp. 85-99, 2012.

[19] J. McCollough, "The effect of income growth on the mix of purchases between disposable goods and reusable goods," Int. J. Consum. Stud., vol. 31, no. 3, pp. 213-219, 2007.

[20] T. Cooper, "Inadequate Life?Evidence of Consumer Attitudes to Product Obsolescence," $J$. Consum. Policy, vol. 27, no. 4, pp. 421-449, Dec. 2004.

[21] E. M. Okada, "Trade- ins, Mental Accounting, and Product Replacement Decisions," J. Consum. Res., vol. 27, no. 4, pp. 433-446, Mar. 2001.

[22] J. McCollough, "Consumer discount rates and the decision to repair or replace a durable product: a sustainable consumption issue," J. Econ. Issues, vol. 44, no. 1, pp. 183-204, 2010.

[23] A. Calabrese and F. De Francesco, "A pricing approach for service companies: service blueprint as a tool of demand-based pricing," Bus. Process Manag. J., vol. 20, no. 6, pp. 906-921, 2014.

[24] L. Yang, P. Guo, and Y. Wang, "Service pricing with loss averse customers," Available SSRN 2418303, 2014.

[25] S. Huber and S. Spinler, "Pricing of full-service repair contracts," Eur. J. Oper. Res., vol. 222, no. 1, pp. 113-121, Oct. 2012.

[26] C. Barrot, J. U. Becker, and J. Meyners, "Impact of service pricing on referral behaviour," Eur. J. Mark., vol. 47, no. 7, pp. 1052-1066, 2013.

[27] H. Ro, "Complaint, patience, and neglect: responses to a dissatisfying service experience," Serv. Bus., vol. 8, no. 2, pp. 197-216, 2014.

[28] B. S. Blanchard, D. Verma, and E. L. Peterson, Maintainability: a key to effective serviceability and maintenance management, vol. 13. John Wiley \& Sons, 1995. 
[29] A. Coulibaly, R. Houssin, and B. Mutel, "Maintainability and safety indicators at design stage for mechanical products," Comput. Ind., vol. 59, no. 5, pp. 438-449, 2008.

[30] F. Ardente, F. Mathieux, and M. Recchioni, "Recycling of electronic displays: Analysis of preprocessing and potential ecodesign improvements," Resour. Conserv. Recycl., vol. 92, pp. 158171, Nov. 2014.

[31] P. Gupta, S. Gupta, and O. P. Gandhi, "Modelling and evaluation of mean time to repair at product design stage based on contextual criteria," J. Eng. Des., vol. 24, no. 7, pp. 499-523, 2013.

[32] S. Behdad and D. Thurston, "Disassembly and reassembly sequence planning tradeoffs under uncertainty for product maintenance," J. Mech. Des., vol. 134, no. 4, p. 41011, 2012.

[33] D. Regazzoni and C. Rizzi, "Digital Human Models and Virtual Ergonomics to Improve Maintainability," Comput. Aided. Des. Appl., vol. 11, no. 1, pp. 10-19, 2014.

[34] A. R. Mashhadi, B. Esmaeilian, W. Cade, K. Wiens, and S. Behdad, "Mining consumer experiences of repairing electronics: Product design insights and business lessons learned," $J$. Clean. Prod., vol. 137, pp. 716-727, 2016.

[35] R. Clift and A. Druckman, "Taking Stock of Industrial Ecology."

[36] A. Käki, "Forecasting in End-Of-Life Spare Parts Procurement.” Citeseer, 2007.

[37] S. I. Ahmed, S. J. Jackson, and M. R. Rifat, "Learning to fix: knowledge, collaboration and mobile phone repair in Dhaka, Bangladesh," in Proceedings of the Seventh International Conference on Information and Communication Technologies and Development, 2015, p. 4.

[38] T. S. Glickman and F. Xu, "The distribution of the product of two triangular random variables," Stat. Probab. Lett., vol. 78, no. 16, pp. 2821-2826, 2008.

[39] W. M. Cheung and V. Pachisia, "Facilitating waste paper recycling and repurposing via cost modelling of machine failure, labour availability and waste quantity," Resour. Conserv. Recycl., vol. 101, pp. 34-41, Aug. 2015.

[40] M. Krystofik, J. Wagner, and G. Gaustad, "Leveraging intellectual property rights to encourage green product design and remanufacturing for sustainable waste management," Resour. Conserv. Recycl., vol. 97, pp. 44-54, Apr. 2015.

[41] J. Han, M. Kamber, and J. Pei, Data mining: concepts and techniques: concepts and techniques. Elsevier, 2011.

[42] S. Hu and Z. Wen, "Why does the informal sector of end-of-life vehicle treatment thrive? A case study of China and lessons for developing countries in motorization process," Resour. Conserv. Recycl., vol. 95, pp. 91-99, Feb. 2015.

[43] M. Sabbaghi, B. Esmaeilian, A. Raihanian Mashhadi, W. Cade, and S. Behdad, "Reusability Assessment of Lithium-ion Laptop Batteries Based on Consumers Actual Usage Behavior," J. Mech. Des., Sep. 2015. 